\title{
Using super-high resolution satellite imagery to census
}

\section{threatened albatrosses}

Running title: Albatross census by satellite

\section{PETER T. FRETWELL ${ }^{1 *}$, PHILLIP SCOFIELD ${ }^{2}$, and RICHARD A. PHILLIPS ${ }^{1}$}

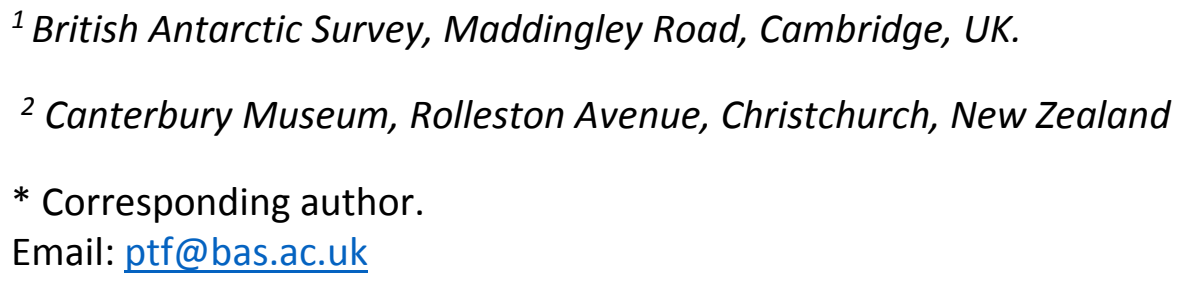

This study is the first to utilize $30 \mathrm{~cm}$ resolution imagery from the WorldView-3 (WV-3) satellite to directly count wildlife. We test the accuracy of the satellite-method for directly counting individuals at a well-studied colony of wandering albatross Diomedea exulans at South Georgia, and then apply it to the closely-related northern royal albatross D. sanfordi, which is near-endemic to the Chatham Islands and of unknown recent population status due to the remoteness and limited accessibility of the colonies. At South Georgia, satellite-based counts were comparable to ground counts of wandering albatross nests, with a slight over-estimation due to the presence of non-breeders. At the Chatham Islands, satellite-based counts of northern royal albatross in the 2015/16 season were similar to those at the Forty Fours, but much lower than at The Sisters in 2009/10, which is of major conservation concern for this endangered albatross species. We conclude that the ground-breaking resolution of the newly available WV-3 satellite will provide a step change in our ability to count albatrosses and other large birds directly from space without disturbance, at potentially lower cost and with minimal logistical effort.

Keywords: Albatross, remote sensing, satellite imagery 
Keywords:

26

27

28

remote sensing, population monitoring, aerial survey, satellite imagery, Worldview-3, Very High Resolution

\section{Introduction}

Over the last decade, Very High Resolution (VHR) satellite imagery has been used in a number of studies to identify and count wildlife directly. Most of these have focused on the polar regions, where breeding locations are remote and the contrast between animals and their surrounding environment is often high (Larue \& Knight, 2014). A small minority of these projects have counted individual animals, including polar bears Ursus maritimus (Stapleton et al. 2014), seals (LaRue et al. 2011; McMahon et al. 2014), wildebeest Connochaetes spp. (Yang et al. 2015) and southern right whales Eubalaena australis (Fretwell et al. 2014), and most were part of small-scale, proof-ofconcept studies. Population sizes of penguins have been estimated at larger scales by satellite, including in two species across the Antarctic continent by extrapolation from the area of penguin huddles, or of guano staining (Fretwell et al. 2012; Lynch \& Larue, 2014). To date, no remotesensing study has used satellite imagery to count all the individuals of one species at a global scale; however, with the recent launch of new, higher spatial-resolution, satellites, this may now be possible.

Seabirds are one of the most threatened of all groups of birds according to the Red List criteria of the World Conservation Union (IUCN) (Croxall et al. 2012). Albatrosses and large petrels are particularly at risk, largely as a result of incidental mortality (bycatch) in fisheries and, for some species, disease, predation or habitat destruction by alien species at breeding colonies (Phillips et al. 2016). Of the six species in the 'great' albatross genus Diomedea, two are listed by IUCN as Critical, one as Endangered and three as Vulnerable, and almost all pairs nest in remote islands in the southern oceans (Phillips et al. 2016). These are amongst the largest, and have some of the longest 
wingspans, of flying birds, and the upper body in the adults of most species is predominantly white. They are therefore excellent models for testing the limits of detection of individual animals using WorldView-3 imagery, particularly as information on their population trends is integral to their conservation.

This study focuses on two taxa; the wandering albatross Diomedea exulans and the northern royal albatross $D$. sanfordi, which are classified as Vulnerable and Endangered, respectively, by IUCN (Phillips et al. 2016). The wandering albatross has a circumpolar distribution, with breeding populations at South Georgia, Prince Edward Islands, Iles Kerguelen, Iles Crozet and Macquarie Island, has an estimated global population of circa 8,360 pairs, and is considered to be decreasing largely because of incidental mortality in long-line fisheries (Jiménez et al. 2014, Phillips et al. 2016). The northern royal albatross has a much more restricted breeding range (confined almost entirely to three islands in the Chatham group $(<1 \%$ of the population breed on the South Island, New Zealand), and is the fifth rarest of the 22 albatross species, with the global population estimated as c.5,800 pairs in 2002 (Phillips et al. 2016). The classification of the northern royal albatross as Endangered is on the basis of the small area of occupancy, and the high rate of population decline predicted from poor breeding success in the late 1980s and 1990s; this followed a severe cyclonic storm in 1985 which stripped soil and vegetation from nest sites and led to high rates of failure from egg breakage, exposure to high temperatures and flooding during incubation (Robertson 1998). As the breeding islands are unpopulated, small, remote and difficult to access, monitoring of population size and productivity from aerial or ground surveys has been intermittent; however, the increase from an estimated 5,200 breeding pairs in 1995, to 5,800 breeding pairs in 2002 at the Chathams indicates a partial recovery (BirdLife International 2017).

The aims of this study were to test the accuracy and utility of using WorldView-3 imagery to count great albatrosses, and to determine the population size and trends of northern royal albatrosses. To validate the method, we compared counts of wandering albatross nests derived from satellite 
80

imagery (Apparently Occupied Sites; AOS) with those of nests from ground surveys at a well-studied location at South Georgia, where nests are monitored intensively throughout the breeding season. We then used WorldView-3 imagery to count northern royal albatrosses, which nest in broadly similar habitats in terms of topography and vegetation height at the Chatham Islands, to provide an up-to-date population estimate for this endangered species.

\section{Materials and Methods}

\section{Study areas}

Bird Island $\left(54^{\circ} 00^{\prime} \mathrm{S}, 38^{\circ} 03^{\prime} \mathrm{W}\right)$. This is a small island $\left(<1 \mathrm{~km} x<5 \mathrm{~km}\right.$; area $\left.\sim 4.5 \mathrm{~km}^{2}\right)$ to the west of mainland South Georgia (Fig.1), which held $61 \%$ of the breeding population of wandering albatrosses at South Georgia in austral summer 2003/04, equivalent to c. $10 \%$ of the global population (Poncet et al. 2006; Phillips et al. 2016). The birds nest in relatively flat areas of tussock grass Poa flabellata, which they used to construct nest mounds.

The Chatham Islands $\left(44^{\circ} 23^{\prime} \mathrm{S}, 176^{\circ} 17^{\prime} \mathrm{W}\right)$ group lies $680 \mathrm{~km}$ east of New Zealand and consists of one large island, ten smaller islands, and other sea stacks. Ninety-nine percent of the global population of northern royal albatross breed on three of the smaller islands: Big and Little Sister (usually termed the Sisters) and, farther to the east, the Forty Fours (Phillips et al. 2016) (Fig. 1). The three small islands in the Chatham Group are precipitous and have no easy access, ground visits are extremely difficult and the distance of the islands from mainland New Zealand means that aerial surveys are expensive. The other $1 \%$ of the global population breed at Taiaroa Head on the South Island, New Zealand, which is accessible and monitored regularly. 
One of the main limitations in the use of satellites for counting individual animals is the resolution (Laliberte \& Ripple, 2003). In March 2015, the U.S. Congress relaxed restrictions on the spatial resolution of commercial satellite imagery from $50 \mathrm{~cm}$ to $30 \mathrm{~cm}$, ushering in a new era of super-high resolution optical satellite imagery for scientific and other applications. The threshold size of objects that can be seen from space is now much smaller, and the definition, and reliability with which they can be discriminated, are much improved. WorldView-3 is currently the only satellite providing commercial imagery at sub- $40 \mathrm{~cm}$ resolution, specifically optical imagery at a spatial resolution of 31 $\mathrm{cm}$ in the panchromatic band, and of 1 metre in the visible and near-infrared bands

(http://www.satimagingcorp.com/satellite-sensors/worldview-3/). This more than doubles the potential density of pixels from 4 pixels per $\mathrm{m}^{2}$ (for a $50 \times 50 \mathrm{~cm}$ resolution image) to 10.4 pixels per $\mathrm{m}^{2}(31 \mathrm{~cm} \times 31 \mathrm{~cm})$. For wildlife applications, there are therefore more species of which individual animals are potentially visible, or can be visualized at considerably higher definition by satellite than previously.

The study was based on WorldView-3 VHR satellite images, with the visible bands (2/3/5) pansharpened to provide a $31 \mathrm{~cm}$ resolution colour image using the Gram Schmidt algorithm in ENVI image processing software. To account for topographic distortion and to ensure that GPS ground truthed nest locations matched as close as possible to the pixels in the image, the satellite imagery of Bird Island, South Georgia ( $54^{\circ} 00^{\prime} \mathrm{S}, 38^{\circ} 03^{\prime} \mathrm{W}$ ) was orthorectified using a high resolution ( $5 \mathrm{~m}$ cell size), photogrammetrically-compiled digital elevation model (DEM) (British Antarctic Survey, 2000). As no ground truthing data for the Chatham Islands were available, orthorectification was not possible. The image of Bird Island, South Georgia $\left(54^{\circ} 00^{\prime} \mathrm{S}, 38^{\circ} 03^{\prime} \mathrm{W}\right)$ was acquired on 10 January 2016, by which time all pairs of wandering albatrosses have laid, based on the latest egg date in the intensive study area (5 January), and a small percentage had failed (see Results). Images of the Forty Fours and of the Sisters in the Chatham Islands, were acquired in 2016 on 12 February and 19 
February, respectively. This corresponds to the mid to late brood-guard period for northern royal albatrosses. Hence, one adult (rarely two) from each pair will be present at each nest with a chick, and nonbreeders may also be in attendance, although given the later stage in the season, at a smaller proportion of sites than in the image of Bird Island. In addition, an archived image of the Sisters (but not the Forty Fours) was available, from 29 December, 2015; this date corresponds to the mid incubation period for northern royal albatrosses. The satellite imagery was clear and cloud free, and covered $100 \%$ of the islands. Counts of these images (see below) were compared with those in photographs taken in aerial surveys in late December 2009.

\section{Ground truthing data}

Wandering albatrosses at Bird Island have been monitored intermittently from 1958, and annually since 1980. This involves daily visits to a study area of 100-150 nests that are staked and mapped (with a handheld GPS, accurate to $<10 \mathrm{~m}$ ) to determine laying, hatching and fledging dates, and weekly visits at other times to determine timing of failure and breeding success. All other breeding areas on the islands are visited every 1-2 weeks in incubation; all nests with eggs are staked and mapped with handheld GPS, and the nests visited at least monthly thereafter to determine timing of failure, and breeding success.

In addition to birds incubating eggs (and a few partners), pre-breeders (birds that have never bred), deferring breeders, and a small number of failed breeders attend the colony in the early to midbreeding season (hereafter, these last three groups of birds are termed "nonbreeders"). It is necessary to adjust for the presence of these nonbreeders (errors of commission), to estimate the 
number of breeding pairs from counts of birds in satellite (or other) imagery. Hence, counts of wandering albatrosses in seven digital camera photographs taken from vantage points overlooking nesting sites at Bird Island during early to mid-incubation (15 January to 14 February, 2015) were compared with ground counts of the number of nests with eggs in those areas. Each of these photographs was counted twice to improve accuracy.

Great albatrosses breed on elevated, flat or gently sloping terrain, and tend to prefer areas of tussock or other grassy vegetation that provides the material for their nests. The head, back and upper tail of an adult wandering or northern royal albatross are largely white, although with dark vermiculation on some feathers, and they have a body length of $107-135 \mathrm{~cm}$ (BirdLife International 2017). Individual birds are therefore likely to show as several white pixels in the WordView-3 satellite imagery, given the $31 \mathrm{~cm}$ cell size (Fig. 2). The upper wing surface also includes dark feathers, and so the size of the white dot is not necessarily much bigger in a bird with extended wings that is displaying on the ground, or in flight.

\section{Satellite image counts}

As albatross were clearly evident as white dots in the satellite imagery, these were counted on screen directly from the WorldView-3 image, i.e., by eye, in separate polygons of $200 \mathrm{~m} \times 200 \mathrm{~m}$ (roughly the area that fits within a single screen at the scale the birds were counted). Dots on the image were digitized manually in ArcMap 10.1. (Environmental Systems Resource Institute, Redlands, California). Due to the positional errors associated with a handheld GPS, and the distortion inherent in the orthorectified image, matching of individual nest locations on the ground on a one-to-one basis with those in the satellite imagery was not possible, and therefore our main comparisons were of total counts of wandering albatrosses on Bird Island. 
Previous studies have found that oblique aerial photographic surveys provide an effective means of counting various species of albatrosses in remote locations (Wolfaardt \& Phillips 2013, Robertson et al. 2013). In a comparison of different techniques, Robertson et al. (2013) found that aerial photography identified more of the nesting birds than other methods (yacht-based photography, ground counts, quadrat sampling and point-distance sampling), and that there was minimal variance $(0.28 \%)$ between duplicate counts. Super-high resolution satellite imagery provides a similar resource to aerial photography, but has a coarser resolution, and we found that the variance among counters was somewhat higher than from aerial photography (see results). We therefore increased the number of counters of the digital satellite imagery to four, to better understand the variance between counters. However, the large coverage of satellite imagery has the advantage that stitching errors, a known source of error in aerial photography mosaics, are avoided.

\section{Results}

Analysis of the oblique digital photography for non-breeding birds

The number of wandering albatrosses counted in hand-held digital photographs exceeded those in the ground counts in the same areas at Bird Island by $0.4 \%$ to $58.3 \%$, or $11.1 \%$ overall, based on mean values in areas counted twice (Table 1). The greatest discrepancy (58.3\%) was for the area with the fewest nests and the highest proportion of nonbreeders. Regardless, we would expect counts of AOSs from a satellite image to overestimate the overall number of nests by $11.1 \%$.

\section{Manual counts of wandering albatrosses at Bird Island from satellite imagery}

The four observers counted 935, 910, 871 and 862 AOSs of wandering albatrosses at Bird Island in the satellite image taken on 10 January, 2015. The mean value of these figures is 894.5 , with a coefficient of variation (SD / mean) of 3.8\%. The mean figure of 894.5 from the satellite survey is 
on that date ( 9 nests had failed by 10 January, which was the day that the satellite image was acquired). The overestimates are due largely to the presence of nonbreeders, flying birds, and errors of commission where features such as rocks or light substrate were assumed to be birds. Based on the oblique digital photographs, the expected number of individuals in the satellite image would be $754 \times 1.111=837.7$ birds, which is $6.5 \%$ lower than the number of AOSs counted.

The variance between manual counts by different observers showed some geographical consistency in terms of errors of commission; these tended to be in more mountainous areas away from the main nesting sites; on Bird Island the availability of a high resolution DEM facilitated the investigation of outliers in terms of slope; many of the satellite-counted nests that were $>15 \mathrm{~m}$ away from the nearest GPS location of a nest on the ground were found to be in areas of steep slope (above $20^{\circ}$ ). Rocks were also sometimes mistaken for birds, and there were also differences in the threshold size at which white dots were assumed to be birds. Although it was impossible to exactly match individual AOSs from the satellite survey with those on the ground, we compared the numbers in each $200 \times 200$ metre polygon (used to aid the counting procedure). Results indicated that the number of birds counted in each polygon in the satellite image (AOSs) correlated closely ( $r=$ 0.994 ) with the number of nests counted on the ground. In most cases ( 23 of the 27 polygons that contained albatrosses), the count from the satellite image exceeded the ground count.

\section{Manual counts of northern royal albatrosses at the Chatham Islands}

Due to resource constraints, one experienced image analyst whose count at Bird Island was closest to the mean of the four counters undertook the analysis of the Chatham Island imagery. Overall, counting at this site was considered to be slightly more difficult than at Bird Island, especially in areas where vegetation was lacking.

Based on manual counts of the satellite images taken from 29 December, 2015, there were 1096 and 709 AOSs, respectively, on Big Sister and Little Sister (Table 2). Manual counts of the satellite image from mid-February 2016 indicated considerably lower numbers of AOSs; 553 and 429 on Big Sister 
and Little Sister, respectively (Table 2). Unlike for the Sisters, there was no archival image available for the Forty Fours from Digital Globe for earlier in the 2015/16 season. However, in any case, the count of 2632 AOSs on the Forty Fours in February 2016 is very similar to the total count of 2692 from the aerial photographs taken there on 4-9 December 2009, and as breeding numbers and success were much higher than on the Sisters, an earlier image was not required. The numbers of AOSs at the Sisters in the 2015/16 season, particularly those from February 2016, are far lower than those in the previous aerial survey in 2009 , suggesting breeding numbers or success was particularly poor (Table 2).

\section{Discussion}

\section{Accuracy of satellite remote-sensing of great albatrosses}

The count of apparently occupied sites from the WorldView-3 satellite imagery of Bird Island provided a reasonable match with the number of wandering albatross nests in which eggs were laid, based on ground counts, or active nests on the same date after a correction factor was applied. As such, the availability of $30 \mathrm{~cm}$ resolution imagery may herald a new era in the remote monitoring of individual birds, with potentially important applications for management and conservation.

At Bird Island, counts of AOSs from satellite images and photographs were higher than the number of nesting adults. Nesting wandering albatrosses are very conspicuous to ground counters and in oblique photographs, and by those dates, all areas of the island had been visited several times; moreover, the topography of the island is such that few, if any active nests would have been missed. We consider that the ground counts are accurate and that the satellite count did not include undiscovered nests at this site. Based on data from surveys in an area that is monitored daily, all pairs had laid by the time the satellite imagery was taken. Hence, we conclude that the discrepancy between the counts is related to the proportion of nonbreeding birds visiting the island and a 
smaller number of errors of commission that could be rock or flying birds. Nonbreeders are mainly pre-breeding or deferring breeders, as few nests ( 9 of $754 ; 1.2 \%$ ) had failed by the date of the satellite image, and members of those pairs are as likely to be at sea as present on the island. This level of nest failure is well within the variance of the satellite-based counts and hence adds only marginal error to the population estimate. From the analysis of the oblique photographs taken in early to mid-incubation, the percentage of nonbreeding birds varied among areas, but determining whether this is due to time of day, date, habitat type or other factors (e.g. attractiveness of each area to pre-breeders) would require collection and analysis of a larger dataset. Hence, we would urge caution before using the ratio of nonbreeders: breeders recorded in this study to correct counts of wandering or other species of great albatrosses at other sites.

In theory, some errors of commission could have resulted from the presence of other bird species in the same areas, particularly other albatrosses, giant petrels Macronectes spp or brown skuas Stercorarius lonnbergi. However, the three other albatross species (Thalassarche spp. or Phoebetria sp.), skuas, and the dominant (dark) colour morph of giant petrels at Bird Island are smaller and present a much darker upper surface; moreover, the other albatrosses are largely colonial and nest in much steeper terrain. Potential confusion is therefore likely only with the light colour morph of the southern giant petrel Macronectes giganteus; however, this morph is very uncommon at Bird Island (four breeding and one nonbreeding individual in 2004/05 over the whole island; Phillips unpublished data) and so the implications would be minor. previous aerial surveys in 2009 indicates similar numbers of pairs of northern royal albatrosses breeding on the Forty Fours in both these two years; in contrast, the results for the Sisters indicate substantial fewer birds in 2016 than 2009. There is no indication of a technical or other problem with 
the imagery. The image of the Sisters was of good quality, the birds were obvious and, moreover, there were considerable areas of flattish terrain with no AOS on both the islands, unlike on the Forty Fours where almost all the available ground was occupied and nesting density was very high (Fig. 3).

The total of 982 birds on Big and Little Sister taken in February, is only $32 \%$ of the previous count from aerial surveys of the two islands in December 2009 (Table 2). As at Bird Island, counts from both satellite imagery and aerial surveys at the Chatham Islands will have included nonbreeding birds, so the number of active nests will be fewer than these totals. In addition, it is important to note that the images of the Chatham Islands were taken during different breeding phases, with those in February corresponding to the brood-guard period, which lasts for c. 4 weeks post-hatching in great albatrosses, when the parents take turns attending the chick (Tickell, 1968). Relatively few failed breeders are still attending colonies by the time that chicks hatch at successful nests, at least in wandering albatrosses (British Antarctic Survey unpublished data). However, differences in breeding stage per se would not explain the striking contrast between the apparently steep decline on the Sisters, and the stable population on the Forty Fours.

The most likely explanation for the differences between the two Sisters, and the Forty Fours in apparent population trajectories or breeding success is provided by comparing the satellite-based counts of northern royal albatrosses at the Sisters in February 2016, with those from the image acquired on 29 December 2015, fifty two days earlier, and from a previous aerial survey in November 2009 (Table 2). The image from 29 December 2015 corresponds to the mid incubation period, and the numbers of AOSs were $57.9 \%$ and $61.2 \%$ of those counted in early incubation in November 2009. The December 2015 counts were much higher than those from February in the same season (these were just $29.2 \%$ and $37.1 \%$ of the numbers in November 2009). These counts provides a strong indication that failure rates from mid-incubation to the brood-guard period at the Sisters were considerably higher than in great albatrosses at other sites, including the closely-related southern royal albatross Diomedea epomophora (Croxall et al. 1992; Waugh et al. 1997). 
Poor breeding success, if sustained, will ultimately have a major impact on breeding numbers of northern royal albatrosses at the Sisters. Indeed, high levels of breeding failure of this species throughout the Chatham Islands were linked to a cyclonic storm in 1985 (Robertson, 1998); this reduced soil cover and destroyed most of the vegetation, and breeding success was only $18 \%$ from 1990 to 1996 . Although the vegetation recovered gradually, and breeding success improved, there was an estimated 50-60\% reduction in productivity over a 20 year period from 1985 to 2005 (Birdlife International, 2017). Vegetation is needed for nest building and cushioning of eggs and young chicks. Incubating great albatrosses remove the vegetation from the area surrounding the nest and incorporate it into the nest mound, which renders the nest easily visible from above. Lack of vegetation around nests following the cyclones in the 1980s led to egg breakage, high temperatures and flooding (Robertson 2003). Although vegetation cover on the islands was considered to have improved by the late 1990s (Robertson, 2003), our results indicate that breeding success is still considerably lower than before the storm. Values of the Normalised Difference Vegetation Index (NDVI) from Landsat data indicate that vegetation cover on the Forty Fours is good, but on the Sisters is still very poor (authors' unpublished data). This fits well with our results, which indicated that the number of royal albatrosses on the Forty Fours in February 2016 was similar to that in the $2009 / 10$ season, suggesting the population may be broadly stable, whereas numbers on the Sisters were much lower than in 2009/10, suggesting high levels of egg or early chick failure.

The northern royal albatross is long-lived, breeding for the first time at 8-10 years of age and with some adults still breeding aged $>50$ years (Robertson, 1993). Therefore, it will be many years before poor breeding success is reflected in the size of the adult population. Analysis in 2002 suggested that the number of breeding pairs may have remained relatively stable since the 1980s, in spite of the extensive reduction in productivity over a 20-year period (Robertson, 2003). However, our data, collected over a decade later, indicate that low productivity is an issue at least in some years. 
The approach used here to count great albatrosses using WorldView-3 satellite imagery has potential application to the other species in the genus (with the possible exceptions of Antipodean albatross Diomedea antipodensis and Amsterdam albatross D. amsterdamensis which have darker backs), and to other large (with a minimum body size of two pixels; $62 \mathrm{~cm}$ ), surface-nesting seabirds or terrestrial birds with black or white plumage that contrasts with the surrounding substrate, including short-tailed albatross Phoebastria albatrus, gannets Morus spp., pelicans Pelecanus spp. and swans Cygnus spp., provided the nesting density is not too high for individuals to be resolved in the images. These species also have the advantage that they are colonial and the locality of nesting sites is often already known. For the satellite method to be the most economical available, these sites would be in remote areas that are difficult to access, otherwise conventional ground or aerial counts are likely to be cheaper and more effective. However, several of the species, particularly the great albatrosses, not only breed in remote locations, but are considered to be threatened by IUCN and hence require regular monitoring for conservation purposes (Phillips et al. 2016). In these situations, WorldView-3 $30 \mathrm{~cm}$ imagery may be more cost-effective and safer than chartering aircraft or vessels, particularly given the vagaries of the weather. In many islands in the Southern Ocean, persistent cloud cover can be a problem for acquisition of satellite imagery; however, the incubation period of great albatrosses lasts several months, which will usually include a few cloud-free days. Acquisition of satellite data is also completely free of any type of disturbance that may be caused by drone, plane or ground surveys (Giese \& Riddle 1999, Vas et al. 2015).

\section{Acknowledgements}

We would like to thank Cleo Small for her support and helpful comments on the manuscript. This project was supported by funding from RSPB and imagery from the Digital globe foundation. We are 
341 albatrosses at Bird Island. We are also grateful to four referees and the Ibis editors for comments on an earlier version of the manuscript. This study represents a contribution to the Ecosystems Component of the British Antarctic Survey Polar Science for Planet Earth Programme, funded by the Natural Environment Research Council (NERC).

\section{Data archiving}

Data will be archived in the NERC Polar Data Centre based at the British Antarctic Survey.

\section{References}

BirdLife International (2017) Species factsheet: Diomedea sanfordi. Downloaded from http://www.birdlife.org on 09/03/2017..

British AntarcticSurvey (2000) Bird Isalnd, South Georgia. BAS SCISTAMAP Series, Sheet 3. 1:7500 scale map, In: BAS SCISTAMAP Series. British Antarctic Survey, Cambridge.

Croxall, J.P., Rothery, P. \& Crisp, A. (1992) The Effect of Maternal Age and Experience on Egg-Size and Hatching Success in Wandering Albatrosses Diomedea exulans. Ibis, 134, 219-228. (2012) Seabird conservation status, threats and priority actions: a global assessment. Bird Conservation International, 22, 1-34.

Fretwell, P.T., Staniland, I.J. \& Forcada, J. (2014) Whales from space: counting southern right whales by satellite. PloS one, 9 (2) e88655. doi: 10.1371/journal.pone.0088655 global, synoptic survey of a species from space. PloS one, 7 (4), e33751. doi: 
Giese, M. \& Riddle, M. (1999) Disturbance of emperor penguin Aptenodytes forsteri chicks by helicopters. Polar Biology, 22: 366. doi:10.1007/s003000050430

Jiménez, S., Phillips, R.A., Brazeiro, A., Defeo, O. \& Domingo, A. (2014) Bycatch of great albatrosses in pelagic longline fisheries in the southwest Atlantic: contributing factors and implications for management. Biological Conservation 171, 9-20.

Laliberte, A.S. \& Ripple, W.J. (2003) Automated wildlife counts from remotely sensed imagery. Wildlife Society Bulletin, 31, 362-371.

Larue, M.A. \& Knight, J. (2014) Applications of very high-resolution imagery in the study and conservation of large predators in the Southern Ocean. Conservation Biology, 28, 1731-5.

LaRue, M.A., Rotella, J.J., Garrott, R.A., Siniff, D.B., Ainley, D.G., Stauffer, G.E., Porter, C.C. \& Morin, P.J. (2011) Satellite imagery can be used to detect variation in abundance of Weddell seals (Leptonychotes weddellii) in Erebus Bay, Antarctica. Polar biology, 34, 1727-1737.

Vas, E., Lescroel, A., Duriez, O., Boguszewski, G.,Gremillet, D. (2015) Approaching birds with drones: first experiments and ethical guidelines. Biology Letters. 11 (2) DOI: 10.1098/rsbl.2014.0754

Lynch, H.J. \& Larue, M.A. (2014) First global census of the Adelie Penguin. Auk, 131, 457-466.

McMahon, C.R., Howe, H., van den Hoff, J., Alderman, R., Brolsma, H. \& Hindell, M.A. (2014) Satellites, the All-Seeing Eyes in the Sky: Counting Elephant Seals from Space. PloS one, 9

Phillips, R.A., Gales, R., Baker, G.B., Double, M.C., Favero, M., Quintana, F., Tasker, M.L., Weimerskirch, H., Uhart, M., and Wolfaardt, A. (2016) The conservation status and priorities for albatrosses and large petrels. Biological Conservation 201, 169-183.

Poncet, S., Robertson, G., Phillips, R.A., Lawton, K., Phalan, B., Trathan, P.N. \& Croxall, J.P. (2006) Status and distribution of wandering, black-browed and grey-headed albatrosses breeding at South Georgia. Polar Biology, 29, 772-781.

Robertson, C.J.R. (1993) Survival and Longevity of the Northern Royal-Albatross Diomedea epomophora sanfordi at Taiaroa Head 1937-93. Emu, 93, 269-276. 
Robertson, C.J.R. (1998) Factors influencing the breeding performance of the Northern Royal Albatross. Albatross biology and conservation (ed. by G. Gales), pp. 99-104. Surrey Beatty \& Sons, hipping Norton, Australia.

Robertson, C.J.R. (2003) Albatrosses (Diomedeidae). Grzimek's Animal Life Encyclopedia 8 Birds I Tinamous and Ratites to Hoatzins (ed. by M. Hutchins), pp. 113-116, 118-119. Gale Group, Farmington Hills, MI.

Robertson, G., Moreno, C.A., Lawton, K., Kirkwood, K., Valencia, J. (2008) Comparison of census methods for black-browed albatrosses breeding at the Ildefonso Archipelago, Chile Polar Biology, 31, 153-162

Stapleton, S., LaRue, M., Lecomte, N., Atkinson, S., Garshelis, D., Porter, C. \& Atwood, T. (2014) Polar Bears from Space: Assessing Satellite Imagery as a Tool to Track Arctic Wildlife. PloS one, 9 (7), e101513. doi: 10.1371/journal.pone.0101513.

Tickell, W.L.N. (1968) The biology of the great albatrosses, Diomedea exulans and Diomedea epomophora. Antarctic Bird Studies (ed. by W.L.N. Tickell), pp. 1-56. American Geophysical Union, Washington.

Waugh, S.M., Sagar, P.M. \& Paull, D. (1997) Laying bates, breeding success and annual breeding of southern Royal Albatrosses Diomedea epomophora epomophora at Campbell island during 1964-69. Emu, 97, 194-199.

Wolfaardt, W., \& Phillips, R. (2013) ACAP Guideline census methodologies for albatrosses and petrels http://www.acap.aq/en/resources/acap-conservation-guidelines/2187-censusguidelines/file accessed on 7th December 2016.

ZhenG Yang, T.W., Skidmore, A.K., de Leeuw, J., Said, M.Y., Freer, J. (2014) Spotting East African mammals in Open Savannah from Space, PLOSone 9, 12). http://dx.doi.org/10.1371/journal.pone.0115989 
418 Table 1. Comparison of counts of wandering albatrosses in digital photographs of nesting areas at 419 Bird Island with the number of nest sites recorded during previous ground surveys.

420

\begin{tabular}{|c|c|c|c|c|c|c|}
\hline Photo & Date & $\begin{array}{c}\text { Count } \\
1\end{array}$ & $\begin{array}{c}\text { Count } \\
2\end{array}$ & Mean & $\begin{array}{c}\text { Ground- } \\
\text { truthed } \\
\text { nests }\end{array}$ & $\begin{array}{c}\text { Percentage } \\
\text { error }\end{array}$ \\
\hline DSC_0107 & 15 January 2015 & 43 & 48 & 45.5 & 38 & $+19.7 \%$ \\
\hline DSC_0181 & 15 January 2015 & 120 & 121 & 120.5 & 113 & $+6.6 \%$ \\
\hline DSC_0182 & 15 January 2015 & 118 & 115 & 116.5 & 116 & +0.43 \\
\hline DSC_4473 & 14 February 2015 & 45 & 50 & 47.5 & 30 & $+58.3 \%$ \\
\hline Total & & 326 & 334 & 330 & 297 & $+11.1 \%$ \\
\hline
\end{tabular}

421

422

423 
Table 2. Comparison of satellite and aerial counts* in 2009, 2015 and 2016 for the three breeding

425 locations of northern royal albatrosses in the Chatham Islands

426

427

\begin{tabular}{|l|c|c|c|}
\hline Island & $\begin{array}{c}\text { Brood-guard, } \\
\text { Feb. 2016 }\end{array}$ & $\begin{array}{c}\text { Mid incubation, } \\
\text { 29 Dec. 2015 }\end{array}$ & $\begin{array}{c}\text { Early incubation } \\
\text { Nov. 2009* }\end{array}$ \\
\hline Forty Fours & 2632 & n.a. & 2692 \\
\hline Big Sister & 553 & 1096 & 1893 \\
\hline Little Sister & 429 & 709 & 1159 \\
\hline
\end{tabular}

428 
431 Figure 1. The location of the two study areas. A: Bird Island, South Georgia. The pink area depicts the 432 area covered by the WorldView-3 satellite image taken on 10 January 2016. B: The location of The 433 Sisters and Forty Fours in the Chatham Islands. The red areas depict the areas covered by the 434 WorldView-3 satellite images; these images are in the two C and D. Cloud-free satellite imagery 435 covered the full extent of the study area. 

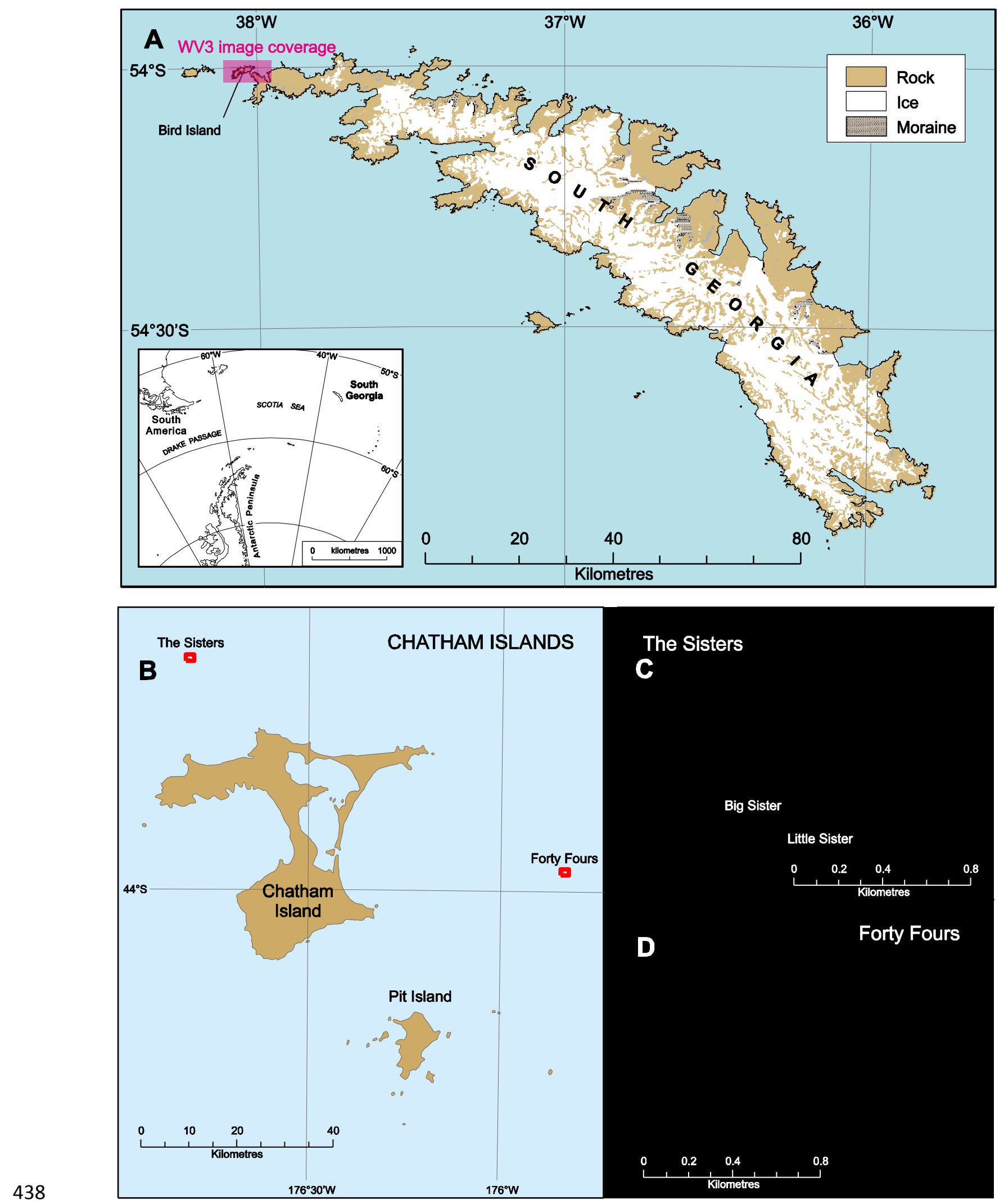


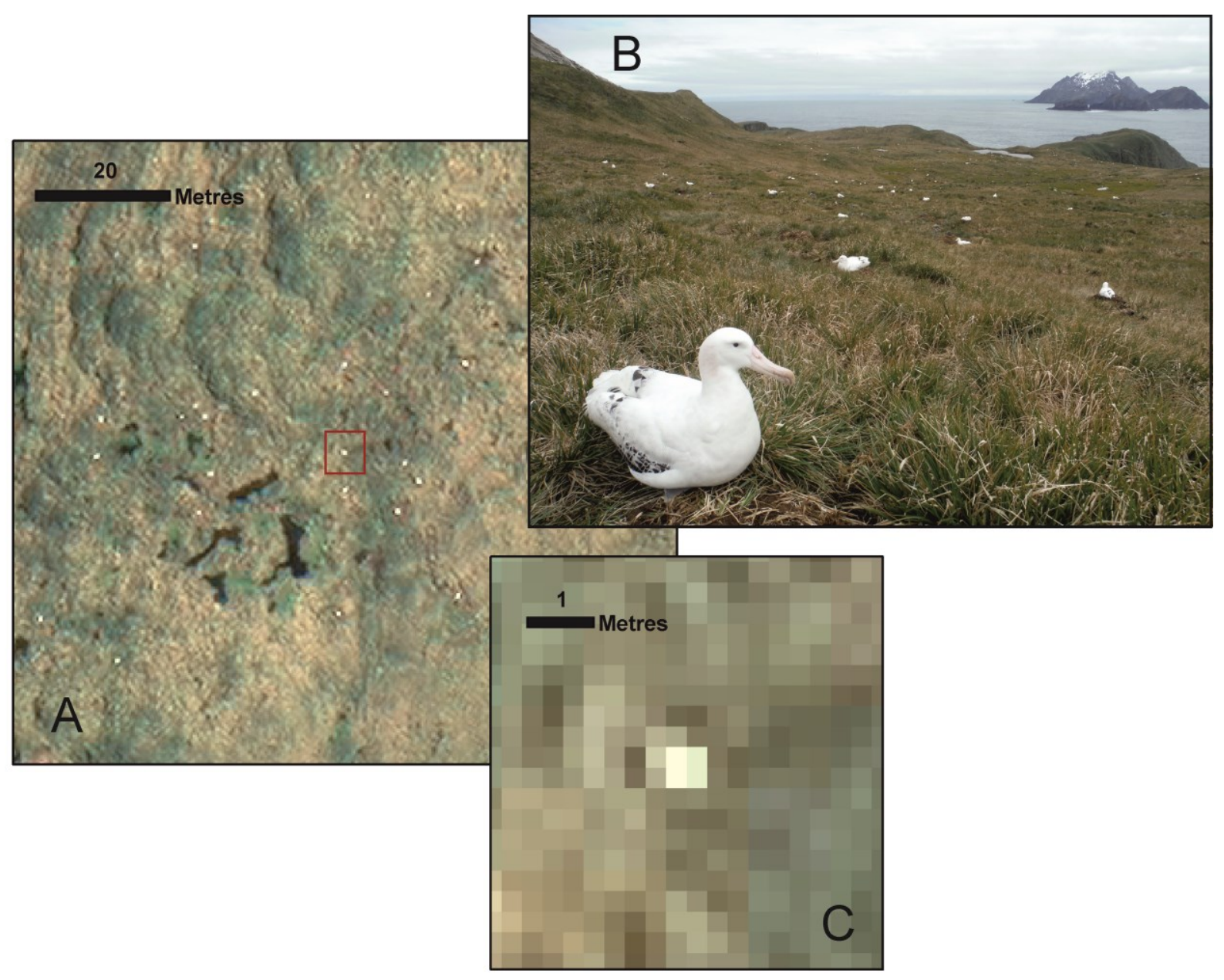

443 Figure 2. A. Part of the WorldView-3 satellite image of Bird Island showing the distribution of white 444 dots. B. Photograph of Bird Island for comparison (photo credit: R.A Phillips). C. Close-up of a representative white dot in panel $A$, indicating pixel composition. 

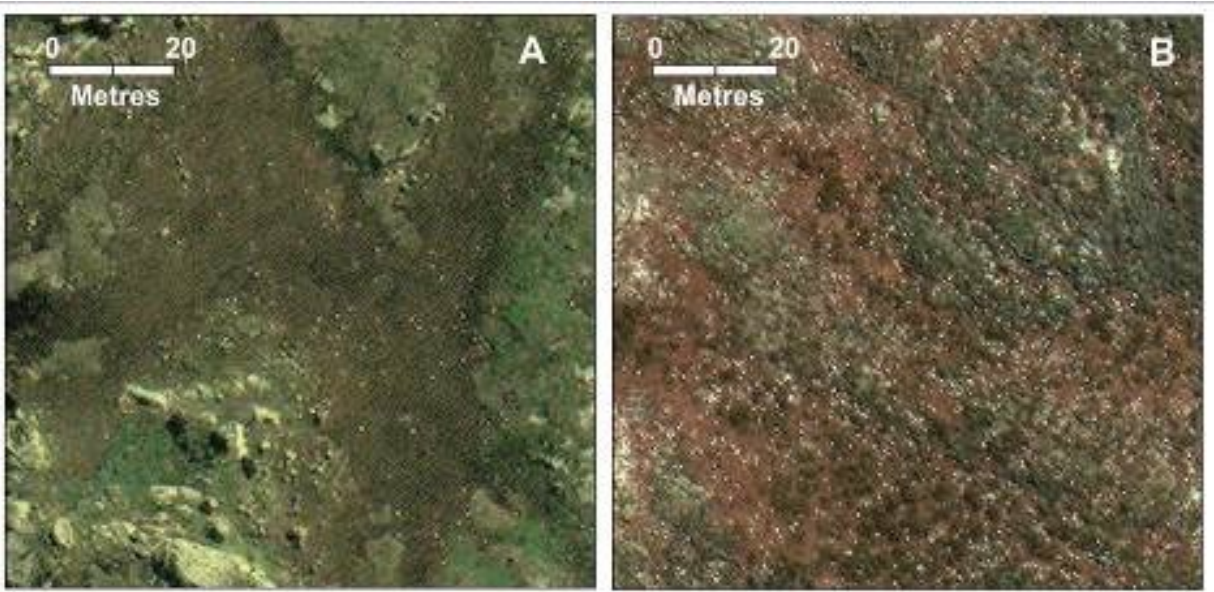

Figure 3. WorldView-3 satellite image snapshots of the Chatham Islands from February 2016 showing white dots assumed to be northern royal albatrosses. Image A shows a typical area on Little Sister, and Image B shows a typical area on the Forty Fours; note the difference in densities of birds. 